\title{
ANALISIS POTENSI TAMAN WISATA AROMA PECCO DI KECAMATAN KAYU ARO BARAT KABUPATEN KERINCI
}

\author{
Mezi Nobela ${ }^{1}$, Rahmanelli $^{2}$ \\ Program Studi Pendidikan Geografi \\ Fakultas Ilmu Sosial, Universitas Negeri Padang \\ Email :Mezynobela11@gmail.com
}

\begin{abstract}
Abstrak
Penelitian ini bertujuan untuk mengetahui potensi taman wisata di lihat dari atraksi wisata, amenitas, aksesibilitas dan potensi tapak Taman Wisata Aroma Pecco di Kecamatan Kayu Aro Barat Kabupaten Kerinci. Jenis penelitian yakni deskriptif kualitatif.Informan penelitian adalah Kepala Desa Bento, staff dari Dinas Pemuda Olahraga Pariwisata dan Kebudayaan Kabupaten Kerinci dan pengunjung Taman Wisata.Teknik pengumpulan data adalah observasi, wawancara dan dokumentasi.Teknik analisis data adalah reduksi data, penyajian data, kesimpulan dan matching (pencocokan). Adapun hasil penelitian sebagai berikut : 1) atraksi wisata sebagian besar masih mengandalkan dari alam 2) Amenitas masih kurang 3) Aksesibilitas mudah di jangkau 4) Potensi tapak taman wisata yaitu flying fox, rumah pohon, bola air, tempat bersepeda, tempat pemancingan, warung/rumah makan, toko souvenir, toko makanan khas daerah, pusat pemantau, tempat sewa sepeda, dan nama taman.
\end{abstract}

Kata Kunci : potensi wisata, atraksi, amenitas, aksesibilitas, tapak wisata.

\section{Abstract}

The aims of this study to find out the potention of the park in the view of tourist attractions, amenitas, accessibility and potential footprint of Aroma Pecco Park in District Kayu Aro Barat Kerinci Regency. The research type is descriptive qualitative. The research informants are headman of Bento, staff from Youth Office of Sport Tourism and Culture of Kerinci Regency, and visitors of a tourist park. Data collection techniques are observation, interview, and documentation. Data analysis techniques are data reduction, data presentation, conclusion and matching. The research results are as follows: 1) most tourist attractions still rely on nature 2) Amenitas still lacking 3) Accessibility is easy to reach 4) Potential tread of the tourist park are flying fox, tree house, water ball, cycling place, fishing ground, restaurants, souvenir shops, specialty regional food shops, monitoring centers, bike hire places and park names.

Keywords: potential of tourism, attractions, amenitas, accessibility, potential of tourist sites.

Pendahuluan : Kabupaten Kerinci sebagai wilayah yang beriklim sejuk dengan panorama alami yang sangat indah serta menakjubkan merupakan anugrah potensi wisata Kabupaten Kerinci yang sangat besar.

${ }^{1}$ Artikel ini ditulis dari skripsi penulis dengan judul Analisis Potensi Taman Wisata Aroma Pecco di Kecamatan Kayu Aro Barat Kabupaten Kerinci untuk wisuda periode Maret 2018 dengan Dosen Pembimbing $^{2}$ I Dra. Rahmanelli, M.Pd dan Pembimbing II Ahyuni, ST, M.Si 


\section{PENDAHULUAN}

Menurut Yoeti (1996: 160-162) potensi adalah segala sesuatu yang terdapat di daerah tujuan wisata dan merupakan daya tarik agar orang orang mau datang berkunjung ke tempat tersebut.

\section{Kabupaten Kerinci}

memiliki banyak potensi di bidang pariwisata tapi nampak nya pemerintah Kabupaten Kerinci belum berfokus pada bidang pariwisata, ini terbukti dengan tidak adanya Dinas Pariwisata yang berdiri sendiri melainkan merupakan bagian dari Dinas Pemuda Olahraga Pariwisata dan Kebudayaan hal ini mengakibatkan pengembangan dan pengelolaan suatu daya tarik wisata di Kabupaten Kerinci terjadi seadanya dan cenderung melambat.

Selanjutnya Yoeti (1996 : 151), untuk menjadi daerah tujuan wisata (DTW) suatu daerah harus mengembangkan tiga hal agar menarik untuk di kunjungi yaitu: (a) adanya sesuatu yang dapat dilihat (something to see), (b) adanya sesuatu yang dapat dibeli (something to buy), (c) adanya sesuatu yang dapat dilakukan (something to do).

Salah satu objek wisata di Kabupaten Kerinci yang memiliki potensi yang perlu dikembangkan yaitu Aroma Pecco di Kecamatan Kayu Aro Barat. Objek wisata Aroma Pecco merupakan taman wisata yang menawarkan pemandangan indah dengan lokasi yang sangat sejuk cocok digunakan untuk liburan bersama keluarga. Namun masih banyak potensi yang belum dikembangkan secara maksimal, fasilitas di objek wisata masih belum lengkap. Dalam tiga tahun terakhir ini, Taman Wisata Aroma Pecco belum menampakkan perkembangan pengunjung yang mengembirakan. Objek wisata ini belum mampu mampu menahan pengunjung lebih lama untuk menikmati keindahan alam Taman Wisata Aroma Pecco. Tabel 1 menggambarkan jumlah pengunjung Taman Wisata Aroma Pecco tahun 2012-tahun 2014.

Tabel 1. Jumlah Pengunjung Taman Wisata Aroma PeccoTahun 2012-2014

\begin{tabular}{|c|c|c|c|c|c|}
\hline No & $\begin{array}{c}\text { Objek } \\
\text { Wisata }\end{array}$ & $\begin{array}{c}\text { Wisatawan } \\
\text { Macanegara }\end{array}$ & $\begin{array}{c}\text { Wisatawan } \\
\text { Nusantara }\end{array}$ & $\begin{array}{c}\text { Wisatawan } \\
\text { Lokal }\end{array}$ & Jumlah/Jiwa \\
\hline 1 & 2012 & 210 & 3.040 & 8.300 & 11.550 \\
\hline 2 & 2013 & 320 & 2.430 & 7.900 & 10.650 \\
\hline 3 & 2014 & 205 & 2.245 & 7.600 & 10.050 \\
\hline
\end{tabular}

Sumber:Kantor Dinas Pemuda Olahraga Pariwisata dan KebudayaanKabupaten Kerinci. 
Dari tabel di atas dapat di lihat bahwa jumlah pengunjung Taman Wisata Aroma Pecco semakin berkurang dari tahun ke tahun, untuk membuat Aroma Pecco lebih menarik serta dapat menahan pengunjung lebih lama berada di taman wisata perlu pengelolaan dan pengembangan yang serius dari berbagai pihak baik itu pemerintah maupun masyarakat.

Menurut Bakaruddin (2008 : 52), ada beberapa faktor yang sangat menentukan perkembangan pariwisata yaitu : (a) adanya kebebasan untuk bergerak dalam artian melakukan perjalanan, (b) adanya sarana transportasi dan komunikasi, (c) adanya sarana akomodasi dan caterring, (d) adanya daya tarik di daerah tujuan wisata (DTW), (e) terjaminnya keamanan di daerah tujuan wisata (DTW), (f) adanya faktor kemudahan yang lebih besar untuk mengunjungi daerah tujuan wisata (DTW), (g) dan tersedianya unsur unsur pelayanan yang memadai termasuk bahan bahan sarana informasi.

Berdasarkan fakta di atas, artikel ini perlu kajian tentang potensi Taman Wisata Aroma Pecco di lihat dari atraksi wisata, amenitas, aksesibilitas dan potensi tapak Taman Wisata Aroma Pecco di Kecamatan Kayu Aro Barat Kabupaten Kerinci.

Suwantoro (1997:

mengemukakan bahwa, atraksi wisata adalah ciptaan manusia seperti kesenian, festival, pesta ritual, upacara perkawinan tradisional, khitanan, dan lain lain). Atraksi dibagi ke dalam dua golongan yaitu atraksi alam dan atraksi buatan manusia, atraksi alam adalah daya tarik wisata yang melekat pada keindahan dan keunikan alam dari Pencipta yang mana terdiri dari keindahan alam (natural amenities), iklim, pemandangan, fauna dan flora yang aneh (uncommon vegetation \& animals), hutan (the sylvan elements), dan sumber kesehatan (health centre) seperti sumber air panas belerang, mandi lumpur dan atraksi buatan manusia adalah segala sesuatu yang menjadi daya tarik wisata yang diciptakan atau dibuat oleh manusia, misalnya: monumen, candi, art gallery, kesenian, festival, pesta ritual, upacara perkawinan tradisional, dan lain-lain.

Menurut Rusita (2016) amenitas berkaitan dengan kebutuhan akan fasilitas dan utilitas, amenitas adalah fasilitas pendukung demi kelancaran kegiatan pariwisata yang juga ditujukan untuk memberikan kenyamanan kepada wisatawan. Amenitas bukan terdapat pada daerah tujuan wisata namun pada dasarnya amenitas dibutuhkan pada saat wisatawan melakukan perjalanan ke tempat tujuan wisata, fasilitas tersebut terdiri dari akomodasi, rumah makan, pusat informasi wisata, toko 
cinderamata, pusat kesehatan, Kerinci, informan penelitian berjumlah keamanan, sarana komunikasi, 16 orang yang terdiri dari Kepala Desa ketersediaan air bersih dan listrik. Bento, staff dari Dinas Olah Raga Seiring dengan itu, Mill (2000: 27) Pemuda Pariwisata dan Kebudayaan mengatakan "accessibilities of the tourist destination, yaitu semua yang dapat memberi kemudahan kepada wisatawan untuk datang berkunjung pada suatu daerah tujuan wisata (DTW).

Kemudian Soekadijo (2000) mengatakan bahwa persyaratan aksesibilitas terdiri dari akses informasi di mana fasilitas harus mudah ditemukan dan mudah di capai, harus memiliki akses kondisi jalan yang dapat dilalui dan sampai ke tempat objek wisata, serta harus ada akhir tempat suatu perjalanan oleh karena itu harus selalu ada (a) akses informasi (b) akses kondisi jalan menuju objek wisata (c) terminal, setidak-tidaknya tempat parkir.

\section{METODE PENELITIAN}

Jenis penelitian yang digunakan dalam penelitian ini adalah penelitian deskiriptif dengan pendekatan kualitatif untuk mendeskripsikan kondisi objek wisata dilihat dari atraksi, amenitas dan aksesibilitas dan potensi tapak yang ada di Taman Wisata Aroma Pecco di Kecamatan Kayu Aro Barat Kabupaten Kerinci, yang dilakukan pada bulan Sepetember - Oktober 2017 di Desa Bento Kecamatan Kayu Aro Barat Kabupaten Kabupaten Kerinci, dan pengunjung taman wisata.

Teknik pengambilan data menggunakan purposive sampling, sumber data utama dari penelitian ini yaitu data primer data yang berkaitan dengan hasil wawancara dengan informan penelitian yang berhubungan dengan analisis potensi taman wisata Aroma Pecco.

Teknik analisis data yang digunakan untuk kondisi taman wisata dilihat dari atraksi wisata, amenitas dan aksesibilitas menggunakan reduksi data, penyajian data, dan menarik kesimpulan atau verifikasi dan untuk potensi tapak taman wisata menggunakan pencocokan (matching).

\section{HASIL DAN PEMBAHASAN}

\section{Atraksi Wisata di Taman Wisata Aroma Pecco}

Menurut Mill (2000 : 26) attractions, yaitu semua yang menjadi daya tarik mengapa wisatawan tertarik datang berkunjung pada suatu daerah tujuan wisata (DTW).

Menurut Hadinoto (1996:27) aktivitas wisata merupakan penggerak dari atraksi wisata, aktivitas wisata dapat berupa jalan kaki, berakit, 
bersepeda, menyelam, berlayar, dan panjat tebing.

Berdasarkan hasil wawancara dengan pengelola, kepala desa, dan pengunjung bahwasanya daya tarik di Taman Wisata Aroma Pecco sebagian besar masih mengandalkan atraksi alam, seperti taman, perkebunan teh yang dijadikan untuk tempat berfoto, udaranya sejuk, pohon pohon besar dan rindang yang bagus untuk tempat piknik bersama teman dan keluarga. Atraksi buatan untuk anak-anak berupa wahana bermain seperti ayunan, jungkat jungkit, dan prosotan. Ketika libur lebaran disediakan tempat bernyanyi untuk pengunjung di atas panggung, dan pada hari hari tertentu pengunjung dapat menyewa perahu dan sepeda air untuk berkeliling danau, dan ada penampilan tari tradisional ketika ada kunjungan pejabat daerah. Hal tersebut belum cukup, masih perlu penambahan wahana permainan lainnya, karena tidak banyak aktivitas wisata yang dapat dilakukan pengunjung dan permainan yang ada masih kurang bervariasi. Dari hasil penelitian tersebut atraksi di Taman Wisata Aroma Pecco masih kurang karena, dalam artian objek wisata ini belum mampu menahan pengunjung untuk berlama-lama bertahan di taman wisata.

\section{Amenitas di Taman Wisata Aroma Pecco}

Amenitas adalah fasilitas pendukung yang ditujukan untuk memberikan kenyamanan kepada wisatawan. Fasilitas tersebut terdiri dari akomodasi, rumah makan (restorasi), pusat informasi wisata, toko cinderamata, pusat kesehatan, keamanan, sarana komunikasi, ketersediaan air bersih dan listrik.

Berdasarkan hasil wawancara dengan pengelola, kepala desa, dan pengunjung, bahwasanya amenitas di Taman Wisata Aroma Pecco sudah ada yaitu terdapat mushola yang bisa menampung sekitar 30 orang, 2 buah toilet dengan sumber air berasal dari danau, tempat duduk dan tempat istirahat untuk pengunjung berupa pondok-pondok (gazebo) yang tersebar di seluruh Taman Wisata Aroma Pecco serta dilengkapi dengan tempat sampah. Namun demikian masih banyak fasilitas yang belum terpenuhi, seperti belum adanya warung permanen sehingga pengunjung harus membawa makanan dari luar taman, belum ada nya rambu-rambu peringatan, sehigga pengunjung harus hati-hati dalam memilih tempat duduk di dekat pohon, karena ada di beberapa pohon terdapat sarang lebah. Seolaholah Taman Wisata Aroma Pecco terkesan masih kurang bersih, belum terdapat pusat informasi yang cukup sehingga pengunjung harus mencari 
petugas apabila ada sesuatu hal yang dibutuhkan pengunjung. Belum adanya pusat kesehatan, jika terjadi kecelakaan pengunjung langsung di bawa ke puskesmas terdekat yaitu puskemas yang ada Desa Bento, dan belum terdapat peginapan di sekitar taman. Ditemukan bahwa fasilitas di Taman Wisata Aroma Pecco masih terkesan belum memadai, sehingga pengunjung merasa kesulitan ketika berada di taman wisata ini.

\section{Aksesibilitas di Taman Wisata Aroma Pecco}

Menurut Mill (2000: 27) mengatakan "accessibilities of the tourist destination, yaitu semua yang dapat memberi kemudahan kepada wisatawan untuk datang berkunjung pada suatu daerah tujuan wisata (DTW).

Dan sejalan dengan pendapat ahi di atas, Seokadijo (1996) mengatakan bahwa persyaratan aksesibilitas terdiri dari akses informasi, dimana fasilitas harus mudah ditemukan dan mudah di capai, harus memiliki akses kondisi jalan yang dapat dilalui dan sampai ke tempat objek wisata, serta harus ada akhir tempat suatu perjalanan. Oleh karena itu, harus ada akses informasi, akses kondisi jalan menuju objek wisata, terminal dan tempat parkir.

Berdasarkan temuan di lapangan, bahwasa akses ke Taman Wisata Aroma Pecco mudah di jangkau karena jarak dari jalan raya sekitar 50 meter, dan dari ibukota kabupaten jaraknya sekitar $16 \mathrm{~km}$ dengan waktu tempuh dengan waktu 1 jam berkendaraan (kendaraan pribadi, angkutan umum) Kondisi jalan ke Taman Wisata Aroma Pecco tidak terlalu baik, karena ada sebagian jalan dari ibukota kabupaten yang berlubang dan dari pintu masuk taman wisata jalan nya masih jalan tanah bercampur pasir, serta belum terdapat tempat parkir permanen sehingga tempat parkir di taman ini tidak teratur.

Hasil di lokasi penelitian bahwasa akses di Taman Wisata Aroma Pecco sudah cukup baik karena lokasi taman mudah di jangkau, jalan yang mudah di lalui walaupun kondisi jalan tidak terlalu baik, dan tempat parkir di Taman Wisata Aroma Pecco yang belum permanen.

\section{Potensi Tapak Wisata di Taman Wisata Aroma Pecco.}

Berdasarkan hasil wawancara dengan pengelola, maka disepakati untuk membangun beberapa fasilitas penunjang seperti; (a) flying fox, pembuatan flying fox di taman wisata, baik dengan menggunakan konstruksi permanen ataupun atau semi permanen di taman wisata rata-rata dengan diameter disesuaikan dengan besar dan letak pohon. Di taman wisata tidak berada di tepi tebing dan tanah 
gembur, pengelola setuju untuk pembuatan flying fox dengan konstruksi permanen yang di rancang menggunakan menara bukan dari pohon, (b) rumah pohon, peneliti, pengelola, dan pengunjung setuju untuk pembuatan rumah pohon, karena pohon di taman wisata memiliki diameter yang besar dan tinggi, serta letak pohon yang berdiameter besar tidak berdekatan. Lokasi untuk pembuatan rumah pohon peneliti ingin menampilkan pemandangan alam yaitu perkebunan teh dan Gunung Kerinci. Dan pengelola ingin menampilkan pemandangan taman dan danau yang ada di tengah tengah taman. Sementara itu, lokasi yang disarankan pengunjung dengan menampilkan pemandangan perkebunan teh, (c) bola-bola air, untuk merancang taman bola-bola air, disetujui untuk pembuatan bola air di bagian ujung danau yang selama ini belum dimanfaatkan. Di sisi kiri dan kanan terdapat pohon yang bisa digunakan untuk mengikat tali bola agar dapat mengontrol bola apa bila terlalu jauh karena waktu maksimal di dalam bola hanya 15 menit, (d) tempat bersepeda, disetujui untuk pembuatan tempat bersepeda di dalam taman yang juga sudah terdapat jalan setapak. Jalan ini dapat digunakan untuk bersepeda dari lokasi taman wisata yang sedikit miring serta sedikit bergelombang, (e) toko souvenir, disepakati dan disetujui untuk pembuatan toko souvenir agar pengunjung bisa membawa cendramata apabila mengunjungi taman dan lokasi. Lokasi pembuatan toko souvenir bisa ditempat yang relatif datar serta berdampingan dengan toko-toko lainnya, (f) toko makanan khas daerah, disetujui untuk pembuatan toko makanan khas daerah sehingga pengunjung bisa menikmati makanan khas dari daerah Kerinci, pembangunan lokasi took makanan direncanakan berdampingan dengan toko souvenir, (g) sewa sepeda, disetujui pembuatan tempat sewa sepeda sehingga pengunjung tidak perlu membawa sepeda dari rumah untuk mengelilingi taman wisata. Lokasi tempat sewa sepeda akan berdampingan dengan toko souvenir dan toko makanan khas, (h) warung/rumah makan, disetujui untuk pembuatan warung atau rumah makan yang sebelumnya belum ada warung atau rumah makan permanen di taman wisata. Lokasi pembuatan warung atau rumah makan direncanakan berlantai tiga yang di bawahnya terdapat toko souvenir, toko makanan khas daerah dan tempat sewa sepeda, (i) pusat pemantau, disepakati untuk pembuatan pusat pemantau lokasi wisata agar petugas bisa memantau pengunjung ke taman wisata, pembuatan pusat pemantau direncanakan berada di lantai tiga, (j) kolam pemancingan, pembangunan kolam pemancingan 
pada kolam yang selama ini belum dimanfaatkan dan hanya di biarkan kosong, tetapi selalu di aliri air dari mata air yang ketinggian kurang lebih 1 meter, dan $(\mathrm{k})$ penamaan taman, untuk penamaan taman-taman yang akan dibangun sebuah "Land Mark" di tempat yang datar yang nantinya akan terlihat dari jalan raya.

Gambaran perencanaan Kawasan Taman Wisata Aroma Pecco menurut peneliti pada gambar 1 .

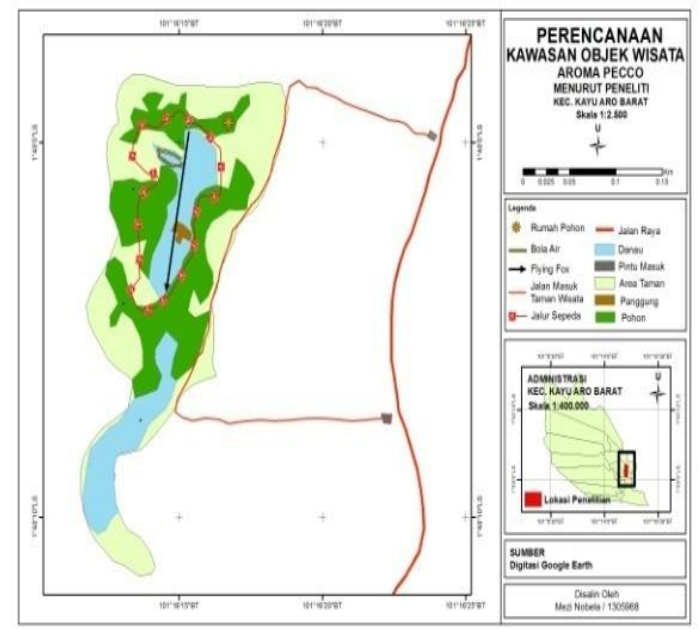

Gambar 1. : Peta Perencanaan Taman Wisata Aroma Pecco menurut peneliti.

Gambaran peta perencanaan Kawasan Taman Wisata Aroma Pecco menurut pengelola dapat di lihat pada gambar 2.

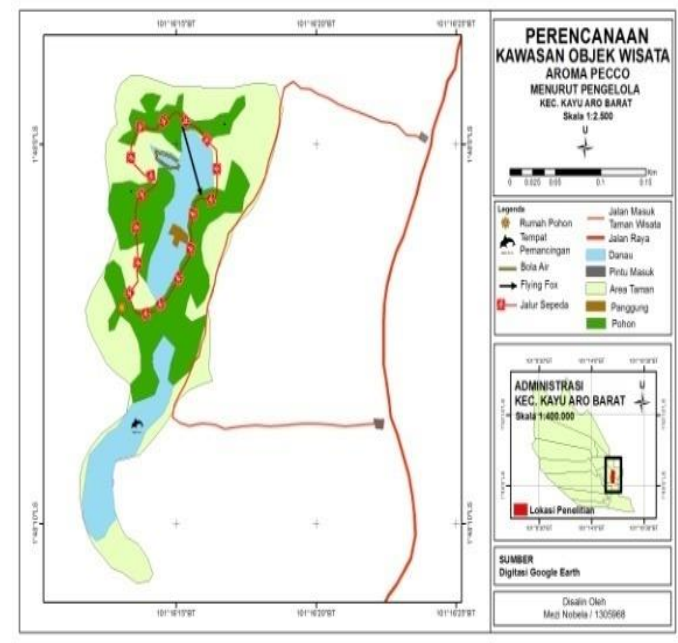

Gambar 2. : Peta Perencanaan Taman Wisata Aroma Pecco menurut pengelola.

Gambaran peta perencanaan Kawasan Taman Wisata Aroma Pecco menurut pengunjung dapat di lihat pada gambar 3.

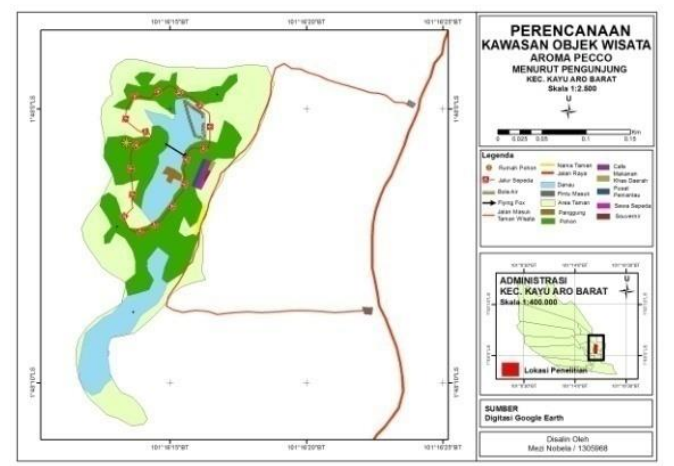

Gambar 3. : Peta Perencanaan Taman Wisata Aroma Pecco menurut pengunjung.

Gambaran peta perencanaan Kawasan Taman Wisata Aroma Pecco dapat di lihat pada gambar 4 . 


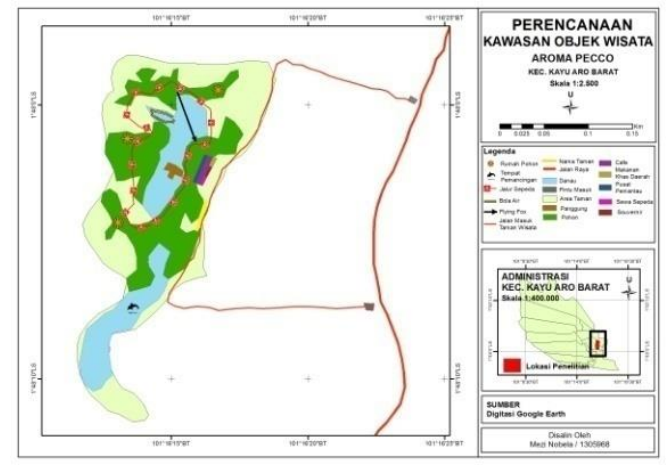

Gambar 4. : Peta Perencanaan Taman Wisata Aroma Pecco.

Dari tiga peta tersebut di atas, nantinya bisa dijadikan acuan untuk menentukan tapak potensi Taman Wisata Aroma Pecco

\section{SIMPULAN DAN SARAN}

1. Atraksi Taman Wisata Aroma Pecco di Kecamatan Kayu Aro Barat sebagian besar masih mengandalkan keindahan alam seperti; a) pemandangan taman, perkebunan teh, sambil menikmati kesejukan udara, pohon-pohon besar dan rindang, , b) tempat khusus anak-anak terdapat wahana bermain seperti; ayunan, jungkat jungkit, prosotan, c) khusus untuk tanggal libur dan lebaran disediakan panggung hiburan untuk pengunjung. Pada hari-hari tertentu, pengunjung dapat menyewa perahu dan sepeda air untuk berkeliling danau, dan ada penampilan tari tradisional ketika ada kunjungan pejabat daerah. Namun penambahan wahana permainan karena belum banyak aktivitas wisata yang dapat dilakukan pengunjung dan permainan yang tersedia masih terkesan kurang bervariasi.

2. Amenitas Taman Wisata Aroma Pecco di Kecamatan Kayu Aro Barat belum lengkap, seperti belum adanya warung permanen, belum ada rambu-rambu peringatan, dan meningkatkan kebersihan Taman Wisata Aroma Pecco. Belum adanya pusat informasi, pusat kesehatan, dan peginapan di sekitar taman. Namun fasilitas lain yang sudah ada diantaranya; mushola, toilet, tempat duduk, dan tempat istirahat berupa pondok-pondok (gazebo) yang tersebar di seluruh taman wisata Aroma Pecco dan sarana tempat sampah sudah ada namun dirasa belum memadai.

3. Aksesibilitas Taman Wisata Aroma Pecco di Kecamatan Kayu Aro Barat mudah di jangkau karena jarak dari jalan raya sekitar 50 meter, dan dari ibukota kabupaten jaraknya sekitar $16 \mathrm{~km}$, dan dapat di tempuh sekitar 1 jam perjalanan dengan menggunakan kendaraaan pribadi ataupun angkutan umum. Kondisi jalan menuju lokasi taman belum baik karena sebagian jalan masih rusak dan berlubangJalan ke pintu masuk taman juga masih tanah bercampur pasir. 
4. Potensi tapak Taman Wisata Aroma Pecco di Kecamatan Kayu Aro Barat Kabupaten Kerinci yang kemungkinan dapat dikembangkan di lokasi taman yaitu; flying fox, rumah pohon, bola air, tempat bersepeda, kolam pemancingan, warung atau rumah makan, toko souvenir, toko makanan khas daerah, pusat pemantau, tempat sewa sepeda, dan 'Land Mark' .

Beberapa hal perlu disarankan antara lain; (a) Pemda dan instansi terkait perlu memperbaiki dan menambah fasilitas agar pengunjung

\section{DAFTAR RUJUKAN}

Bakaruddin. 2008. Perkembangan

Dan Permasalahan

Kepariwisatan. Padang. UNP press.

Hadinoto, Kusudianto.1996.

Perencanaan pengembangan

destinasi pariwisata. Jakarta.

Universitas Indonesia.

Mill, Robert Christie. 2000. Tourism the internasional business. Jakarta. Raja Grafindo Persada.

Rusita dkk. 2016. Studi Potensi Dan Daya Tarik Objek Wisata Alam merasa nyaman dan tertarik untuk ke Taman Wisata Aroma Pecco, (b) Sesuai dengan kebutuhan pengunjung, pemda dan instansi terkait untuk nambaha atraksi wisata agar menjadi daya tarik pengunjung untuk berlamalama menikmati liburan di Taman Wisata Aroma Pecco, (c) pemda, instansi terkait, bersama-sama dengan masyarakat setempat untuk melakukan pengawasan di dalam maupun di luar taman wisata agar pengunjung merasa aman ketika berada di Taman Wisata Aroma Pecco, (d) perlu diadakan penelitian lanjutan oleh peneliti lain untuk variabel yang berbeda.

\section{Air Terjun Wiyono Di Taman Hutan Raya Wan Abdul Rahman Provinsi Lampung. Info teknik. Vol. 17 No 2.}

Suwantoro, Gamal SH.1997. Dasar Dasar Pariwisata. Yogyakarta .ANDI.

Yoeti, Oka. A. 1996. Pengantar Ilmu Pariwisata. Bandung. Angkasa.

Soekadijo, R.G. 2000. Anatomi Pariwisata: Memahami Pariwisata Sebagai "Systemic Linkage. Jakarta: Gramendia Pustaka Utama 